\title{
Linking Changes in Radial Profiles of Sap Flux Density with the Response of Water Vapour Exchange to Water Deficit
}

\author{
V. Hernandez-Santana ${ }^{1}$, M.S. Alvarado-Barrientos ${ }^{2}$, C.M. Rodriguez-Dominguez ${ }^{1}$, \\ A. Perez-Martin ${ }^{1}$ and A. Díaz-Espejo ${ }^{1}$ \\ ${ }^{1}$ Irrigation and Crop Ecophysiology Group, Instituto de Recursos Naturales y \\ Agrobiología de Sevilla (IRNAS, CSIC), Avenida Reina Mercedes, n. ${ }^{\circ} 10,41012$ \\ Sevilla, Spain \\ ${ }^{2}$ Dept. of Natural Resources and the Environment, University of New Hampshire, USA
}

Keywords: sap flux density, radial patterns, Beta function, olive trees, stomatal control, transpiration

\section{Abstract}

Knowledge of temporal variations in radial profiles of sap flux density $\left(J_{s}\right)$ and its relation to canopy water vapour exchange would help to improve our understanding of plant water relations. In this study we aimed to test if there is a consistent radial profile of $J_{s}$ in olive trees under optimal soil water availability and severe water stress conditions. Furthermore, if the radial profile of $J_{s}$ is not consistent through time we aimed to assess whether this radial variability can be explained through differential water exchange response to evaporative demand $(D)$ of sun-exposed, new foliage and shade, old foliage. We measured sap flux density in the trunk of 6-year-old olive trees under two different irrigation treatments: a full irrigation treatment and a treatment replacing $30 \%$ of the of irrigation needs. We related the hourly radial profiles characterized with the Beta probability distribution function with independent water vapour exchange measurements at different exposures in the tree canopy (sun-exposed, young foliage and shade, old foliage). Results showed that under well irrigated conditions the shape of the radial profile of $J_{s}$ hardly varied, but under water deficit situations most of the sap appears to be conducted deeper into the sapwood and $J_{s}$ is also more variable throughout the sapwood. Accordingly, results demonstrated that in shade, old foliage water vapour exchange varied less than in sun-exposed new foliage. As a result, in days under severe water deficit, the contribution of shade old foliage to the whole tree transpiration was greater. Radial profile changes and canopy measurements were found to respond in a similar way to $D$. During conditions of low $D$ and soil water deficit it was observed a greater contribution of the inner xylem to total stem flow and shade, old leaves to canopy gas exchange.

\section{INTRODUCTION}

Establishing quantitative links between hydraulic processes of the stem and the response of stomatal conductance $\left(g_{s}\right)$ to environmental factors such as atmospheric vapour pressure deficit $(D)$ is essential for improving our ability to understand plant water relations (Litvak et al., 2012). Nevertheless, the automation of $g_{s}$ measurements still presents some difficulties and how $g_{s}$ vary within plant canopies has been long considered as a challenging problem. Besides the difficulties to measure $g_{s}$ at canopy level, determining stem hydraulic short-term patterns is also challenging due to inter- and intraspecies heterogeneity observed in the type and arrangement of sap conducting tissue (Swanson, 1994). The radial variation in stem conductance has been widely recognized as a major source of heterogeneity in xylem sap flux density $\left(J_{s}\right)$ (Granier et al., 1994; Nadezhdina et al., 2007; Fiora and Cescatti, 2008) and observed to change through time (Ford et al., 2004). These changes have been widely attributed to water stress (Fernández et al., 2001; Nadezhdina et al., 2007; Poyatos et al., 2007). Specifically, in olive trees temporal radial profile changes of $J_{s}$ have been observed and attributed partly to a greater stomatal control in the sun-exposed, younger foliage (Fernández et al., 1997, 2001) and to vertical distribution of root water uptake (Nadezhdina et al., 2007). In addition, spatial 
distribution of leaf-to-air coupling (McNaughton and Jarvis, 1983; Jarvis and McNaughton, 1986) within individual plant foliage can determine whether transpiration in sun-exposed and shade leaves is differently controlled by $D$ and $g_{s}$ (imposed evaporation, strong coupling) or net radiation (equilibrium evaporation, weak coupling).

Despite several attempts to characterize stem radial profile of $J_{s}$ (Poyatos et al., 2007; Alvarado-Barrientos et al., 2003), the links between the changes in these radial profiles and the spatial patterns of canopy gas exchange are not so well documented (Jiménez et al., 2000; Nadezhdina et al., 2007). Given its importance in this kind of studies, several approaches have been proposed to characterize the radial profile of $J_{s}$ (Ford et al., 2004; Kubota et al., 2005). Notably, a recent work (Caylor and Dragoni, 2009) presented an analytical framework to characterize the radial profile of $J_{s}$ with a probability density function with two terms. One of these terms, describes the location into the sapwood where average $J_{\mathrm{s}}$ is found when expressed in normalized units relative to the sapwood's length (Alvarado-Barrientos et al., 2013), and is claimed to be timeinvariant among trees of the same species providing no severe drought or canopy changes occur (Dragoni et al., 2009).

We aimed to assess the links between radial profiles of $J_{s}$ measured in olive trees (characterized by the above mentioned analytical approach) and independent water vapour exchange measurements at different exposures in the tree canopy. Specifically, our objectives are: (i) to test if there is a consistent shape in radial profiles of $J_{s}$ of olive trees under optimal soil water availability and severe water stress conditions; and, (ii) to assess whether the changes in radial $J_{s}$ are due to changes in a differential transpiration and $g_{s}$ response to $D$ of sun-exposed, new foliage and shade, old foliage. Our hypothesis is that under severe drought the outer part of the sapwood will present less $J_{s}$ as a consequence of greater $g_{s}$ sensitivity to $D$ of sun-exposed, young foliage to which is connected. Thus, we further hypothesize that we will not find a consistent shape in radial profiles of $J_{s}$ among trees under optimal soil water availability and severe water stress conditions.

\section{MATERIALS AND METHODS}

The experiment was conducted in summer of 2012 at the Sanabria orchard, a hedgerow olive commercial orchard (southwest Spain, $37^{\circ} 15^{\prime} \mathrm{N}$; $-5^{\circ} 48^{\prime} \mathrm{W}$ ). The trees, 6-year-old Olea europaea L. 'Arbequina', were planted at $4 \times 1.5 \mathrm{~m}\left(1667\right.$ trees $\left.^{-1}{ }^{-1}\right)$. They are $2.40 \mathrm{~m}$ tall and $1.96 \mathrm{~m}$ wide, run N-NE to S-SW. The area has a Mediterranean climate, annual average precipitation and potential evapotranspiration are $534.0 \mathrm{~mm}$ and $1541.5 \mathrm{~mm}$, respectively. Average maximum and minimum air temperature in the area are 24.9 and $10.7^{\circ} \mathrm{C}$, respectively (period 2002-2012).

The studied trees (Table 1 ) were central individuals located in $12 \times 16 \mathrm{~m}$ plots and were surrounded by 24 border trees. In these plots we had two irrigation treatments: a control treatment where irrigation fulfilled tree water demand (100RDI), and a regulated deficit irrigation treatment in which only $30 \%$ of the water added to control was applied along the whole irrigation season (30RDI). From June 5 (DOY 156) to July 3 (optimal period), all trees in the orchard received enough water to match the crop water requirements. From July 3 the 30RDI treatment was imposed in the corresponding plots drought period). In drought period, 30RDI trees were irrigated one day per week, and in total, the irrigation amounts were $10-15 \%$ of irrigation needs.

The Compensation Heat Pulse (CHP) method (Green et al., 2003) was used to obtain point measurements of sap flux density $\left(J_{s}, \mathrm{~mm} \mathrm{~h}^{-1}\right)$ within the sapwood of the sample trees (Tranzflo NZ Ltd., Palmerston North, New Zealand). One central tree per plot was instrumented in each of three 30RDI plots and two 100RDI plots (Table 1). One probe set was installed into the stem at the east facing side. Each set had two temperature probes, located at $5 \mathrm{~mm}$ upstream and $10 \mathrm{~mm}$ downstream of a linear heater probe. Each temperature probe had four thermocouples, at 5, 1, 15 and $20 \mathrm{~mm}$ below the cambium. Heat pulses (60 J; $60 \mathrm{~W}$ over $1 \mathrm{~s}$ ) were applied once every $30 \mathrm{~min}$. Heat pulses and probes outputs were recorded and stored by a CR10X datalogger connected to a AM25T 
multiplexer (Campbell, Campbell Scientific Ltd., Shepshed, UK). We adopted the approach proposed by Caylor and Dragoni (2009) modified by Alvarado-Barrientos et al. (2013) to characterize the $J_{\mathrm{s}}$ profiles using a unimodal and bounded function, the Betapdf. The radial locations of $J_{s}$ point measurements were normalized by sapwood depth, assuming circumferential homogeneity of the radial profile. A lumped shape parameter, $\rho$, was derived for each hourly radial profile which denotes the radial location relative to the sapwood depth at which average $J_{s}$ is found (Matlab R2010a, The MathWorks, Inc.).

Branch sap flux $\left(F_{s}, \mathrm{~g} \mathrm{~h}^{-1}\right)$ was measured in two branches of the east facing side of the canopy (SGA2 stem-flow gages, Dynamax Inc, Houston, USA). We chose one sunexposed branch with new foliage and one shade branch with old foliage in one tree of 30RDI and 100RDI plots (Table 1). The branches diameters varied between 2.62 and $2.93 \mathrm{~mm} . F_{s}$ is calculated based on the stem heat balance method (SHB) (Sakuratani, 1981; Baker and Van Bavel, 1987) where heat fluxes of the heated stem portion are measured. Data were registered and stored every $30 \mathrm{~min}$ in a Campbell CR10X datalogger connected to AM25T Multiplexer (Table 1).

Air temperature and air humidity was recorded every $30 \mathrm{~min}$ at canopy height and volumetric soil water content $\left(\theta_{\mathrm{v}}\right)$ was determined in every plot with a Profile probe (Delta-T Devices Ltd, Cambridge, UK) connected to a CR1000 Campbell datalogger and two access tubes per plot $\left(\theta_{\mathrm{v}}\right.$ measured at $0.1,0.2,0.3,0.4,0.6$ and $1.0 \mathrm{~m}$ depths).

Measurements of $g_{s}$ were made on two clear days with different $\theta_{\mathrm{v}}$ (DOY 177 $\theta_{\mathrm{v}}=0.233 \mathrm{~cm}^{3} \mathrm{~cm}^{-3}$, and DOY $216 \theta_{\mathrm{v}}=0.174 \mathrm{~cm}^{3} \mathrm{~cm}^{-3}$ ) every $1.5 \mathrm{~h}$ from dawn to dusk in leaves of the same trees where $F_{s}$ was measured (Table 1). We used a Licor LI-6400 portable photosynthesis system (LI-COR, Lincoln NE, USA), with a $2 \times 3 \mathrm{~cm}$ standard chamber, to measure $g_{\mathrm{s}}$ in sun-exposed current-year shoots and in older shade leaves from the inner part of the canopy facing SE, at ca. $1.5 \mathrm{~m}$ above ground. Measurements were taken at ambient light and $\mathrm{CO}_{2}$ conditions.

Significant differences of $\rho$ were tested with the Kruskal-Wallis one way analysis of variance and the Dunn's method for all pairwise multiple comparisons (Sigmaplot 11.0, Systat Software Inc.). The $\mathrm{Ln} D-g_{s}$ linear regressions were compared using Linear Models using "canopy exposure” as a covariate (R package version 2.15.0).

\section{RESULTS}

We analyzed (hourly) radial profiles of $J_{s}$ for 27 days in optimal period and 41 days in drought period, and found non constant $\rho$ among the trees ( $<<0.05$, Fig. 1 ). We used the radial profiles of $J_{s}$ at 8:00 GMT for this analysis because at this time of the day it has been usually reported the maximum daily $g_{s}$ in olive (Fernández et al., 1997), thus a well developed radial profile was expected at this time (Dragoni et al., 2009). Besides differences among trees, those of 30RDI treatment showed a mean $J_{s}$ located deeper into the sapwood during drought period (median $\rho$ : 0.424 and 0.465 in T10 and T11, respectively) compared to optimal period (median $\rho: 0.399$ and 0.454 in T10 and T11, respectively), this difference being statistically significant for one of the 30RDI trees $(\mathrm{p}<0.01$, Fig. 1). This pattern was not observed in the 100RDI tree (median $\rho: 0.419$ and 0.414 in optimal period and drought period, respectively). Furthermore, the variability of $\rho$ in the 100RDI tree was also smaller than during drought period for 30RDI trees (Fig. 1).

We carried out a more detailed analysis of $J_{s}$ comparing two days with similar range of $D$ but different $\theta_{\mathrm{v}}$ due to irrigation $\left(0.053\right.$ and $0.236 \mathrm{~cm}^{3} \mathrm{~cm}^{-3}$ for DOY 205 and 206, respectively). According to the previous results, we found greater and more variable values of $\rho$ for 30RDI trees under severe drought compared to irrigated conditions, and compared to 100RDI trees (Fig. 2). Furthermore, a linear regression analysis demonstrated a different response of $\rho$ to $D$ during contrasting $\theta_{\mathrm{v}}$ for 30RDI trees (Fig. 3). On DOY 205 for low $D$, mean $J_{s}$ was located at deeper radial position into the sapwood than on DOY 206. For high $D$ the response of $\rho$ to $D$ was similar for both days.

Under water stress conditions $F_{s}$ for sun-exposed, new foliage of 30RDI trees, was only recorded in the central hours of the day within the highest $D$ range (Fig. 4). However, in old foliage located inside the tree canopy, $F_{s}$ was measured for a similar 
amount of time in days with contrasting $\theta_{\mathrm{v}}$. For 100RDI trees, patterns were consistent along time (data not shown). Moreover, slightly higher $F_{s}$ values were observed for the shade and old foliage compared to the sun-exposed leaves under low $D$ during days with severe water deficit as opposed to irrigation days when $F_{s}$ was always higher in sunexposed foliage. An analysis of daily ratio values of $F_{s}$ (DOY 178 to 208) between sunexposed and shade branch compared to the corresponding $\rho$ for 30RDI trees at 8:00 GMT, revealed a highly significant albeit weak relationship between these two variables ( $\rho=0.4560-0.0015^{*} F_{s}$ sun $/ F_{s}$ shade, $\left.\mathrm{R}^{2}=0.27, \mathrm{p}=0.01\right)$. Accordingly, $g_{s}$ sensitivity to $D$ decreased more in the sun-exposed, young leaves (56\%) than in the shade, old leaves (37\%) under water stress (Fig. 5). As a result, $g_{s}$ responses to $D$ in sun-exposed and shade foliage were similar under high water deficit (DOY 216), but statistically significant when there was no water deficit (DOY 177).

\section{DISCUSSION}

The approach we used to characterize the radial profile of $J_{s}$ (Caylor and Dragoni, 2009), proved helpful to investigate its short-term variability. We observed tree-to-tree variability in the shape of the radial profile (Fig. 1) in agreement with previous studies (Poyatos et al., 2007; Alvarado-Barrientos et al., 2013) and also diurnally and daily changes within individuals due to different $\theta_{\mathrm{v}}$ (Fig. 2) as predicted by Dragoni et al. (2009). Results showed that under well irrigated conditions the shape of the radial profile of $J_{s}$ hardly varied, but under water deficit situations most of the sap appears to be conducted deeper into the sapwood and $J_{s}$ is also more variable throughout the sapwood. As a result, we found a greater contribution to total stem flow from the inner xylem during conditions of low $D$ and soil water deficit, similar to other studies' results (Granier et al., 1994; Poyatos et al., 2007) but contradictory to others (Ford et al., 2004).

If our hypothesis was true and the outer newest sapwood was mainly connected with sun-exposed young leaves (Jiménez et al., 2002; Nadezhdina et al., 2007), water vapour gas exchange measurements should have showed the radial patterns of $J_{s}$ we found. Accordingly, results demonstrated that for both $F_{s}$ and $g_{s}$, shade, old foliage varied less than sun-exposed new foliage (Figs. 4 and 5) and as a result in days under severe water deficit, the contribution of shade old foliage to the whole tree transpiration was greater. Similarly, Jimenez et al. (2000) found low sap flow rates with little variation in radial pattern in shade suppressed trees, whereas in dominant trees they observed high sap flow rates. Interestingly, the $g_{s}$ sensitivity to $D$ (the slope of $\operatorname{Ln} D-g_{s}$ relationships according to Oren et al., 1999) decreased in sun-exposed leaves under water deficit conditions to levels of shade old leaves (Fig. 5). The greater $\mathrm{g}_{\mathrm{s}}$ response to $\mathrm{Ln} D$ in the morning than in the afternoon may indicate some kind of hysteresis of $g_{s}$ to $D$ reported also in other works (Poyatos et al., 2007; Alvarado-Barrientos et al., 2013). We attribute the weakness of $\operatorname{Ln} D-g_{s}$ relationship of sun-exposed leaves in the optimal period to this hysteresis that do not affect our conclusions. Furthermore, a long-term analysis allowed us to quantitatively link the relative radial position of mean $J_{s}$ with $F_{s \text { sun }}-F_{\text {s shade }}$ ratios, the sap being conducted deeper in the sapwood as $F_{s \text { sun }}-F_{s}$ shade ratios become smaller. A loss of stomatal control due to age and a major decoupling from surrounding atmosphere may explain why old shade, foliage was not as affected as sun-exposed young foliage by water stress conditions (McNaughton and Jarvis, 1983; Jarvis and McNaughton, 1986; Fernández et al., 1997). Important implications of this study are that a characteristic radial profile may be derived for trees considering the water status and meteorological variables, and opens the possibility of using these short-term changes of $J_{s}$ for irrigation programming.

\section{CONCLUSIONS}

The approach we used to characterize the $J_{s}$ radial profile of olive proved useful to explore the link between short-term radial profile shape changes and tree water stress. Sap flux density tended to be higher in the inner xylem during periods with severe drought and low $D$. These changes in the radial profile patterns were explained by different 
response of water vapour exchange in sun-exposed and shade foliage to $D$ under contrasting $\theta_{\mathrm{v}}$. More detailed studies are needed to better understand these links and how they change with environment conditions which could be particularly relevant for irrigation programming.

\section{ACKNOWLEDGEMENTS}

This experiment was funded by the Spanish Ministry of Science and Innovation, research project AGL2009-11310/AGR.

\section{Literature Cited}

Alvarado-Barrientos, M.S., Hernández-Santana, V. and Asbjornsen, H. 2013. Variability of the radial profile of sap velocity in Pinus patula from contrasting stands the seasonal cloud forest zone of Veracruz, Mexico. Agr. Forest Meteorol. 168:108-119.

Baker, J.M. and Van Bavel, C.H. 1987. Measurement of mass flow of water in the stems of herbaceous plants. Plant Cell Environ. 10:777-782.

Caylor, K.K. and Dragoni, D. 2009. Decoupling structural and environmental determinants of sap velocity: Part I. Methodological development. Agr. Forest Meteorol. 149:559-569.

Dragoni, D., Caylor, K.K. and Schmid, H.P. 2009. Decoupling structural and environmental determinants of sap velocity. Agr. Forest Meteorol. 149:570-581.

Fernández, J.E., Moreno, F., Giron, I.F. and Blazquez, O.M. 1997. Stomatal control of water use in olive tree leaves. Plant Soil 190:179-192.

Fernández, J.E., Palomo, M.J., Díaz-Espejo, A., Clothier, B., Green, S., Girón, I.F. and Moreno, F. 2001. Heat-pulse measurements of sap flow in olives for automating irrigation: tests, root flow and diagnostics of water stress. Agric. Water Manage. 51:99-123.

Fiora, A. and Cescatti, A. 2006. Diurnal and seasonal variability in radial distribution of sap flux density: implications for stand transpiration. Tree Physiol. 26:1217-1225.

Ford, C.R., McGuire, M.A., Mitchell, R.J. and Teskey, R.O. 2004. Assessing variation in the radial profile of sap flux density in Pinus species and its effect on daily water use. Tree Physiol. 24:241-249.

Granier, A., Anfodillo, T., Sabatti, M., Cochard, H., Dreyer, E., Tomasi, M., Valentini, R. and Bréda, N. 1994. Axial and radial water flow in the trunks of oak trees: a quantitative and qualitative analysis. Tree Physiol. 14:1383-1396.

Green, S., Clothier, B. and Jardine, B. 2003. Theory and practical application of heat pulse to measure sap flow. Agron. J. 95:1371-1379.

Jiménez, M.S., Nadezhdina, N., Cermák, J. and Morales, D. 2000. Radial variation in sap flow in five laurel forest tree species in Tenerife, Canary Islands. Tree Physiol. 20:1149-1156.

Kubota, M.K., Tenhunen, J., Zimmermann, R. and Shmidt, M. 2005. Influence of environmental conditions on radial patterns of sap flux density of a 70-year Fagus crenata trees in the Naeba Mountains, Japan. Ann. For. Sci. 62:289-296.

Litvak, E., McCarthy, H.R. and Pataki, D.E. 2012. Transpiration sensitivity of urban trees in a semi-arid climate is constrained by xylem vulnerability to cavitation. Tree Physiol. 32:373-388.

McNaughton, K.G. and Jarvis, P.G. 1983. Predicting effects of vegetation changes on transpiration and evaporation. p.1-47. In: T.T. Kozlowski (ed.), Water Deficits and Plant Growth, Vol. 7, Academic Press, New York.

Nadezhdina, N., Nadezhdin, V., Ferreira, M.I. and Pitacco, A. 2007. Variability with xylem depth in sap flow in trunks and branches of mature olive trees. Tree Physiol. 27:105-113.

Oren, R., Sperry, J.S., Katul, G.G., Pataki, D.E., Ewers, B.E., Phillips, N. and Schäfer, K.V.R. 1999. Survey and synthesis of intra- and interspecific variation in stomatal sensitivity to vapour pressure deficit. Plant Cell Environ. 22:1515-1526.

Poyatos, R., Cermák, J. and Llorens, P. 2007. Variation in the radial patterns of sap flux 
density in pubescent oak (Quercus pubescens) and its implications for tree and stand transpiration measurements. Tree Physiol. 27:537-548.

Sakuratani, T. 1981. A heat balance method for measuring water flux in the stem of intact plants. J. Agric. Meteorol. 37:9-17.

Swanson, R.H. 1994. Significant historical developments in thermal methods for measuring sap flow in trees. Agr. Forest Meteorol. 72:113-132.

\section{$\underline{\text { Tables }}$}

Table 1. Measurements dates and trees used in this study.

\begin{tabular}{lccccccc}
\hline \multicolumn{3}{c}{ 30RDI treatment measurements dates } & \multicolumn{5}{c}{ 100RDI treatment measurements dates } \\
(DOY) & \multicolumn{5}{c}{ (DOY) } \\
\hline Tree \# & $\mathrm{J}_{\mathrm{s}}$ profile & $\mathrm{F}_{\mathrm{s}}$ & $\mathrm{g}_{\mathrm{s}}$ & Tree \# & $\mathrm{J}_{\mathrm{s}}$ profile & $\mathrm{F}_{\mathrm{s}}$ & $\mathrm{g}_{\mathrm{s}}$ \\
\hline T5 & $167-208$ & $177-226$ & 177,216 & $\mathrm{~T} 2$ & $177-234$ & & \\
T10 & $177-234$ & & & $\mathrm{~T} 4$ & $167-208$ & $177-226$ & 177,216 \\
T11 & $177-234$ & & & & & & \\
\hline
\end{tabular}

\section{Figures}

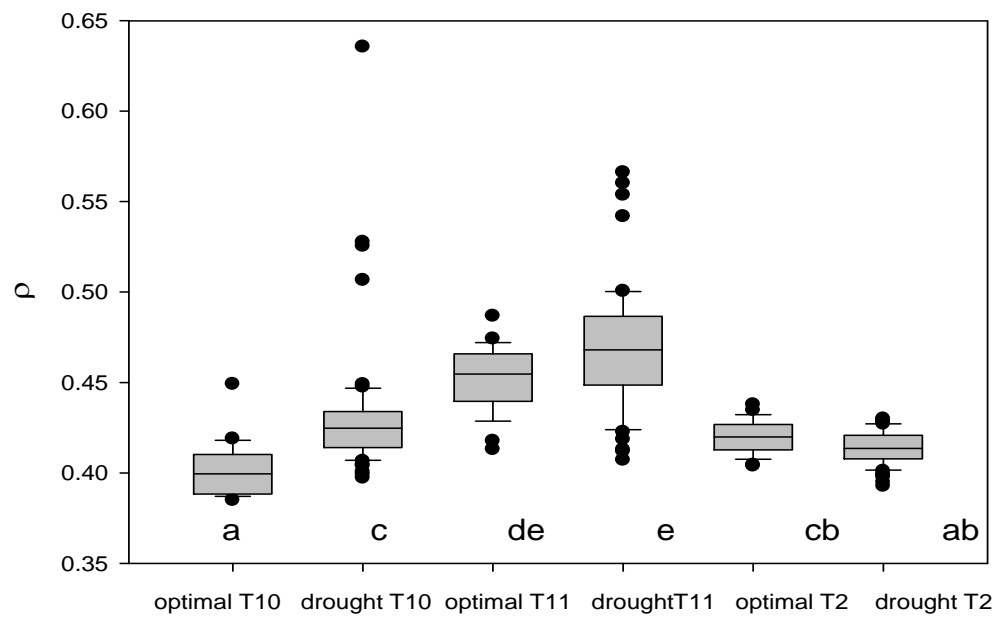

Fig. 1. Box plot with $\rho$ obtained from $J_{s}$ profiles of each studied tree at 8:00 GMT for optimal period and drought period. In each box it is plotted median, $10^{\text {th }}, 25^{\text {th }}, 75^{\text {th }}$ and $90^{\text {th }}$ percentiles, the vertical lines are error bars, and the points the maximums and minimums. Different letters indicate significant different values $(p<0.05)$. 


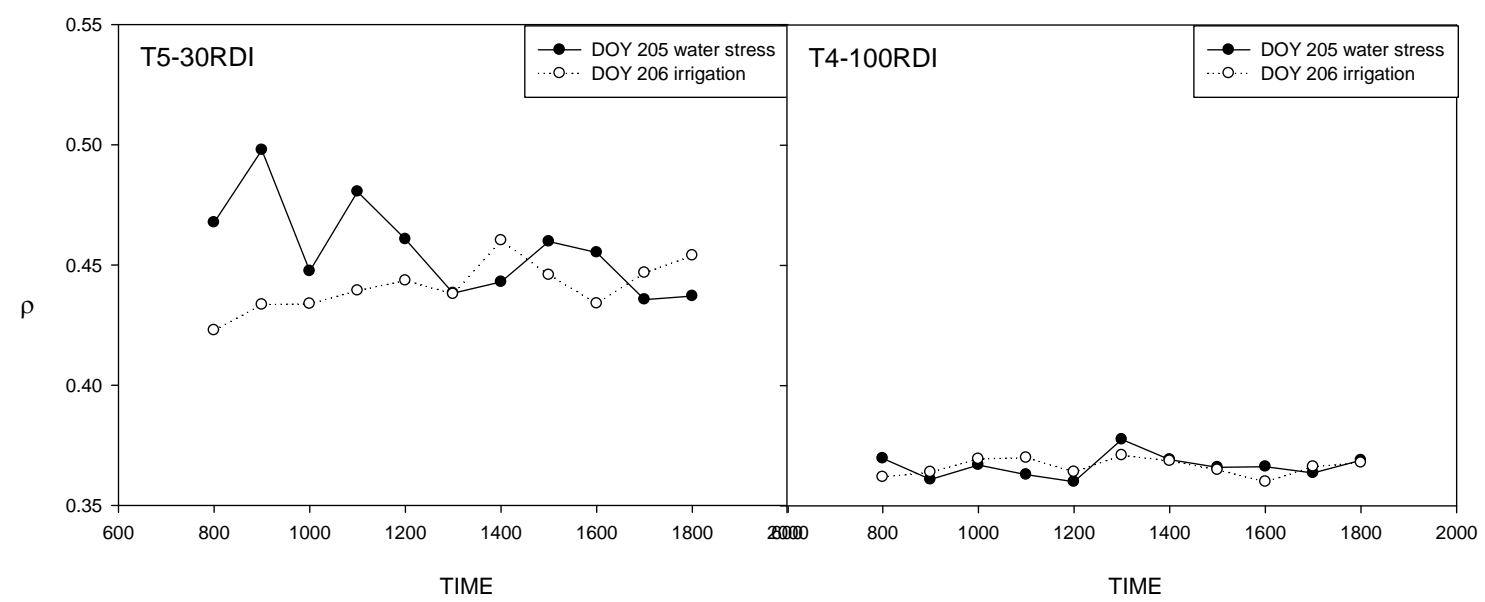

Fig. 2. Diurnal evolution of $\rho$ measured in a sun-exposed, new foliage branch (left panel) and in a shade, old foliage branch (right panel) of two trees under different irrigation regime (30RDI, 100RDI). T5 was irrigated DOY 206 while in DOY 205 there was acute water deficit. T4 was irrigated both days.

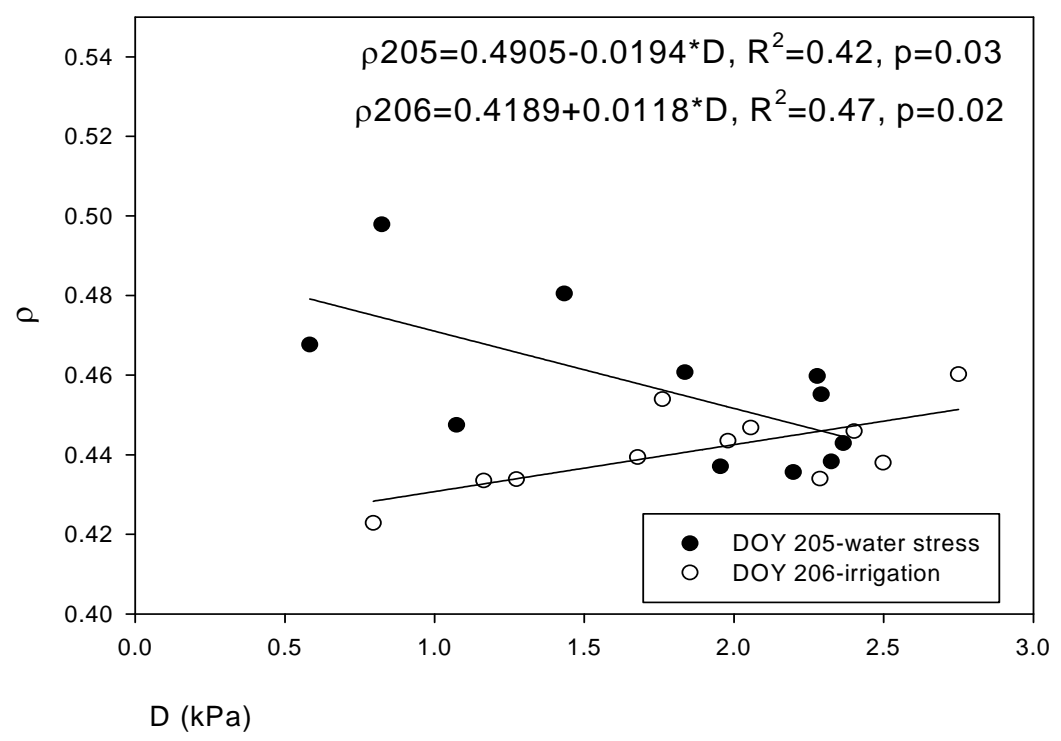

Fig. 3. Relationship between $D$ and $\rho$ for T5 (30RDI) during two days with contrasting $\theta_{\mathrm{v}}$ but similar $D$ range. 


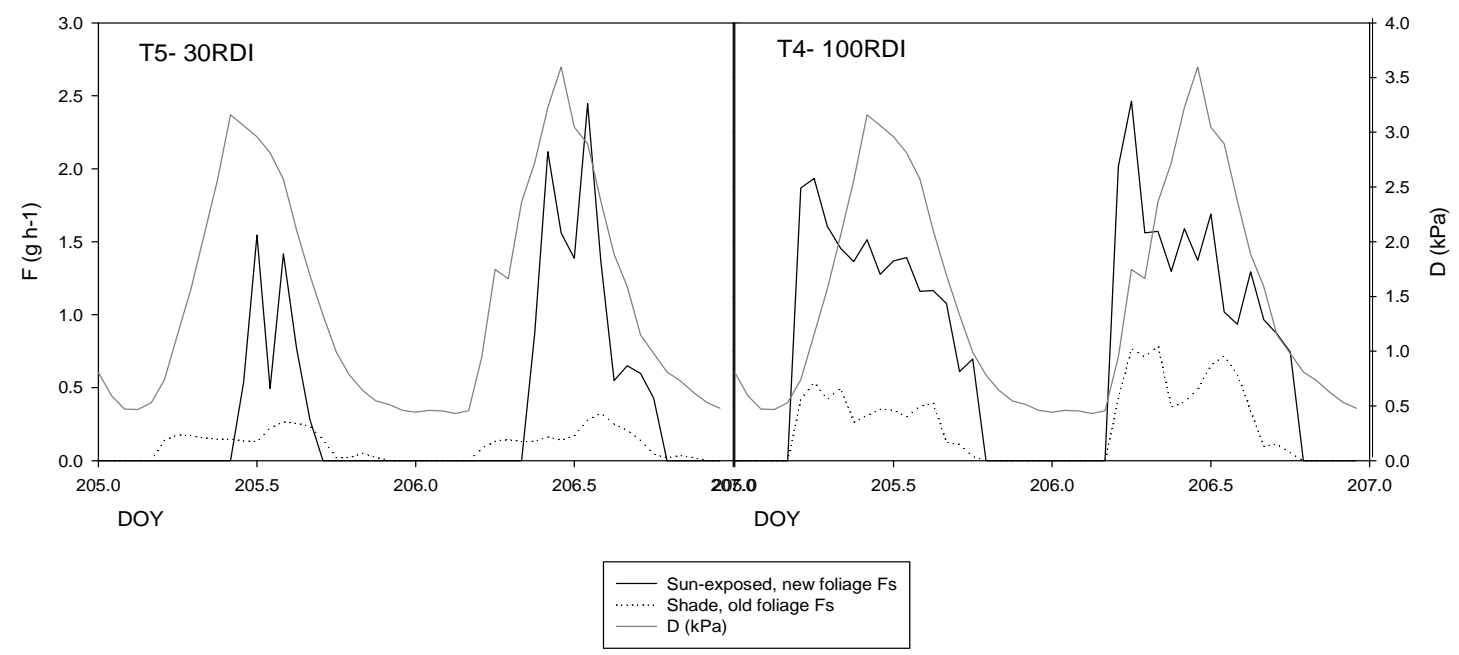

Fig. 4. Diurnal evolution of $F_{s}$ measured in a sun-exposed, new foliage branch and in a shade, old foliage branch of two trees under different irrigation regime (30RDI, 100RDI) but similar $D$ range (grey line). T5 was irrigated DOY 206 while in DOY 205 there was acute water deficit. T4 was irrigated both days.

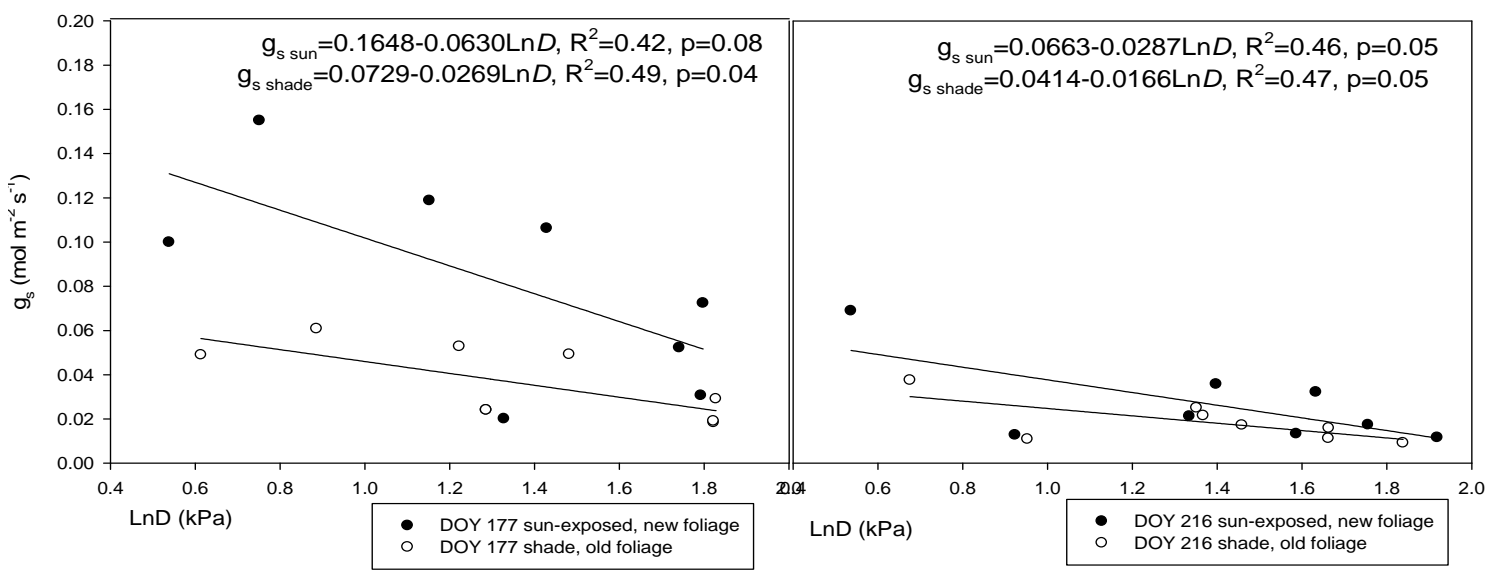

Fig. 5. Relationship between $\operatorname{Ln} D$ and $g_{s}$ in sun-exposed, new foliage and shade, old foliage of T5 (30RDI) in two different days with contrasting soil water content. 